\title{
Effects of granulosa cell co-culture on in-vitro meiotic resumption of bovine oocytes
}

\author{
M. A. Sirard and S. Bilodeau \\ Département de Zootechnie, Université Laval, Québec, Canada GIK 7 P4
}

\begin{abstract}
Summary. This study was undertaken to create an in-vitro model using granulosa cell monolayers to replace the role of the follicle in the maturation of bovine oocytes. Cumulus-oocyte complexes were co-incubated with fresh or 7-day granulosa cell cultures (with new or conditioned medium) or with conditioned medium alone, in the presence or absence of IBMX (isobutylmethylxanthine), adenosine or heparin. Progression to the metaphase-II stage was significantly affected by the co-culture of oocytes with bovine granulosa cell monolayers and to a lesser degree when cultured with supernatant alone (conditioned medium). The oocytes attached rapidly to the monolayer, suggesting that the intimate contact between the granulosa cells and the cumulus-oocyte complexes is an important signal for the maintenance of meiotic arrest. Heparin did not prevent maturation itself, but prevented attachment of cumulus-oocyte complexes to monolayers, thereby reducing their inhibitory effect. Adenosine prevented cumulus expansion and reduced maturation and IBMX was an effective inhibitor only in the presence of additional granulosa cells.
\end{abstract}

Keywords: oocyte; meiosis; granulosa cells; in vitro; cattle

\section{Introduction}

Pincus \& Enzmann (1935) showed that mammalian oocytes, once removed from the precise environment of the follicle, can resume the first meiotic division spontaneously in simple culture media. For cattle, information on the meiotic process is needed to enhance the developmental potential of in-vitro matured oocytes, since one possible cause of developmental defects is the incompetence of oocytes from the smaller follices. If germinal vesicle arrest could be maintained in vitro, it would be possible to influence both the cytoplasm and the nucleus with hormones or granulosa cells before nuclear maturation.

Bovine oocytes are not as sensitive as oocytes from other animals studied to protein kinase stimulation via cAMP accumulation (Sirard \& First, 1988). Results obtained for cattle (Sirard \& First, 1988) and sheep (Moor \& Heslop, 1981) indicate that cAMP accumulation in the oocyte may not be the only physiological way to maintain the meiotic arrest in spite of the fact that bovine oocytes possess an active adenylate cyclase enzyme (Kuyt et al., 1988) and respond temporarily to cAMP variations (Homa, 1988; Sirard \& First, 1988). The effect of isobutylmethylxanthine (IBMX) in cows is similar to the effect of cAMP analogues and results in a delayed breakdown of the germinal vesicle (GVBD) followed by normal maturation or a metaphase-I block (Ball et al., 1984; Sirard \& First, 1988). If denuded oocytes are used, much greater amounts (5 mM, 25 times) of IBMX are required to inhibit GVBD (Homa, 1988). In the mouse, cAMP variations are modulated principally by phosphodiesterase inhibitors, and purines are therefore also effective inhibitors since their major effect is related to the inhibition of phosphodiesterase (Downs et al., 1989). Purines have a weak effect on the meiotic resumption of bovine oocytes (Sirard \& First, 1988) and since bovine follicular fluid does not contain amounts of purines comparable to those 
in the mouse (Downs \& Eppig, 1987; Downs, 1989), it is doubtful that their role is similar in cows.

Sato \& Koide (1984) isolated a small peptide $\left(M_{\mathrm{r}}<10000\right)$ from bovine follicular fluid that was capable of inhibiting meiotic resumption of mouse oocytes in culture. This product has not been tested with bovine oocytes but bovine follicular fluid does have weak meiotic inhibitory properties in vitro (Sirard \& First, 1988). The culture of complete or hemi-sections of the follicular wall is a proven method to maintain meiotic blockage in vitro in the sheep (Moor \& Trounson, 1977), pig (Sato \& Ishibashi, 1977) and cow (M. A. Sirard \& S. Bilodeau, unpublished). Therefore, it is likely that granulosa cells produce an inhibitory factor that: (1) does not diffuse much in follicular fluid, (2) is degraded rapidly in vitro, or (3) is not normally permeable to cumulus-oocyte complexes in vitro. Such a factor could be the small peptide isolated by Sato \& Koide (1984) or a larger molecule such as the Müllerian-inhibiting substance localized in bovine granulosa cells and capable of preventing rat oocyte maturation in vitro (Takahashi et al., 1986). To increase our understanding of the relation between bovine follicular fluid, granulosa cells, purines and cAMP accumulation, we have analysed the effects of co-culture of granulosa cell monolayers and bovine oocytes in vitro.

\section{Materials and Methods}

Recovery of oocytes. Cumulus-oocyte complexes were obtained by follicular aspiration of ovaries collected at the slaughterhouse from cows at different stages of their reproductive cycle. Ovaries were collected in the morning ( $\mathrm{l}$ h) and transported $(1 \mathrm{~h})$ to the laboratory in a saline solution $0.9 \%(\mathrm{w} / \mathrm{v}) \mathrm{NaCl}$ maintained between 30 and $35^{\circ} \mathrm{C}(\mathrm{addi}-$ tives: $100000 \mathrm{IU}$ penicillin, $100 \mathrm{mg}$ streptomycin and $250 \mu \mathrm{g}$ amphotericin B per litre: Sigma Chemical Co., St Louis, MO, USA). Only follicles between 2 and $5 \mathrm{~mm}$ in diameter were aspirated using a 10-ml syringe and an 18-gauge needle. The cumulus-oocyte complexes were recovered in less than $20 \mathrm{~min}$ from follicular exclusion and were selected as described by Leibfried \& First (1979), using unexpanded complete cumulus-surrounded oocytes. Contrary to previous publications (Sirard \& First, 1988), the oocytes (groups of 10-25) were not washed before culture, but transferred immediately with the minimal amount of follicular fluid to their final incubation medium.

Culture of oocytes. Cumulus-oocyte complexes were distributed to multi-weil (24) plates (Corning, NY, USA) containing the culture medium TCM-199 (l ml/well) with Hank's salts, glutamine, bicarbonate and supplemented with $10 \%$ fetal calf serum (Flow Laboratories, McLean, VA, USA) and gentamicin sulphate $(50 \mu \mathrm{g} / \mathrm{ml})$. Four treatments included additives and were used during culture to compare with control (1) medium; (2) isobutylmethylxanthine (IBMX, 0.2 mM), (3) adenosine ( $1 \mathrm{mM})$, (4) IBMX + adenosine and (5) heparin $(100 \mu \mathrm{g} / \mathrm{ml})$. All products were purchased from Sigma Chemical Co. In addition, 5 cell treatments were used for incubation in the 1-ml wells: (1) control (culture medium only), (2) medium plus $2 \times 10^{6}$ fresh granulosa cells, (3) Day-7 monolayers with their conditioned medium, (4) Day-7 monolayers with new medium, and (5) conditioned medium alone. These conditions were used to evaluate the effect of cell supplementation on the meiotic resumption. For each condition the different additives mentioned above were used to evaluate their effect alone (controls without cells) or in combination with the cell treatments. Each individual combination was replicated at least 3 times with the proper controls for each replicate. The incubation lasted for $24 \mathrm{~h}$ at $38.5^{\circ} \mathrm{C}$ in a moisture-saturated atmosphere of $5 \% \mathrm{CO}_{2}$ in air.

Culture of granulosa cells. Bovine granulosa cells were obtained by disruption and aspiration of small follicles (2-5 $\mathrm{mm}$ diameter) with an 18-gauge needle followed by centrifugation $\left(400 \mathrm{~g}, 10 \mathrm{~min}, 4^{\circ} \mathrm{C}\right)$. Subsequently, the cells were washed twice in $30 \mathrm{ml}$ calcium-magnesium-free Hank's balanced salt solution containing antibiotics as described above $\left(400 \mathrm{~g}, 10 \mathrm{~min}, 4^{\circ} \mathrm{C}\right)$. The final pellet was resuspended in $1 \mathrm{ml}$ TCM-199 and cells counted with a haemocytometer. A total of $2 \times 10^{6}$ cells were transferred in each $1-\mathrm{ml}$ culture medium in multi-wells. The plates were cultured at $38.5^{\circ} \mathrm{C}$ in an humidified incubator with $5 \% \mathrm{CO}_{2}$ in air. Culture media were renewed once after $48 \mathrm{~h}$ of culture to remove debris and then left for 5 days to produce the confluence monolayers and conditioned medium used in oocyte culture.

Fixation of oocytes. At the end of the incubation period, the oocytes were transferred in small centrifuge tubes containing $400 \mu \mathrm{l}$ of a trypsin solution $(1 \mathrm{mg} / \mathrm{ml}$ in Hank's balanced solution) and vortex-agitated for $2 \mathrm{~min}$. Completely denuded oocytes were recovered under a stereomicroscope and transferred on glass slides in a small drop of fluid. Vaseline and paraffin wax were used to maintain a coverslip in contact with the oocytes without excessive pressure. The coverslip was then fixed with epoxy glue and the slides immersed in a fixative solution ethanol:acetic acid, $3: 1 \mathrm{v} / \mathrm{v}$ ) for a minimum of $24 \mathrm{~h}$. The slides were stained with $1 \%$ aceto-orcein and examined with phase contrast microscopy at $\times 100$ and $\times 400$ magnification.

Analysis of results. Oocytes were classified as at the germinal vesicle (GV) stage, as intermediate (including germinal vesicle breakdown, early condensation, metaphase-I, anaphase-I and telophase-I), or as matured (metaphase-II). Degenerated oocytes, as defined by a vacuolated or an unevenly stained cytoplasm with often no 
chromatin, were discarded from the evaluation after final analysis showing no treatment effects. Results from all replicates were pooled and the figures submitted to the Waller-Duncan variance test (Waller \& Kemp, 1976). Additionally, the significance of individual comparisons was evaluated by $\chi^{2}$ tests (Snedecor $\&$ Cochran, 1980).

\section{Results}

A total of 1630 selected cumulus-enclosed oocytes were fixed and analysed after the 24-h incubation period. The effects of different cell-culture conditions are illustrated in Fig. 1. The treatment using supernatant medium after 7 days of culture was responsible for a significant diminution in the number of oocytes maturing to the metaphase-II stage compared to control, cultured cells plus new medium and fresh cells $(P<0.05)$. The treatment using cultured cells for 7 days and their own supernatant was significantly better than all other treatments with respect to the lowest fraction of mature oocytes $(P<0.05)$. In this experiment there was a rapid attachment of the cumulus-oocyte complexes to the monolayer; in less than $30 \mathrm{~min}$ after the start of the co-culture incubation, the cumulus-oocyte complexes were adhering to the monolayer strongly enough to remain at the same location if the surrounding medium was agitated. At the end of the incubation period the cumulusoocyte complexes in most treatments (except that with heparin) were so tightly adherent to the monolayers that the underlying granulosa cells were removed with the cumulus-oocyte complexes.

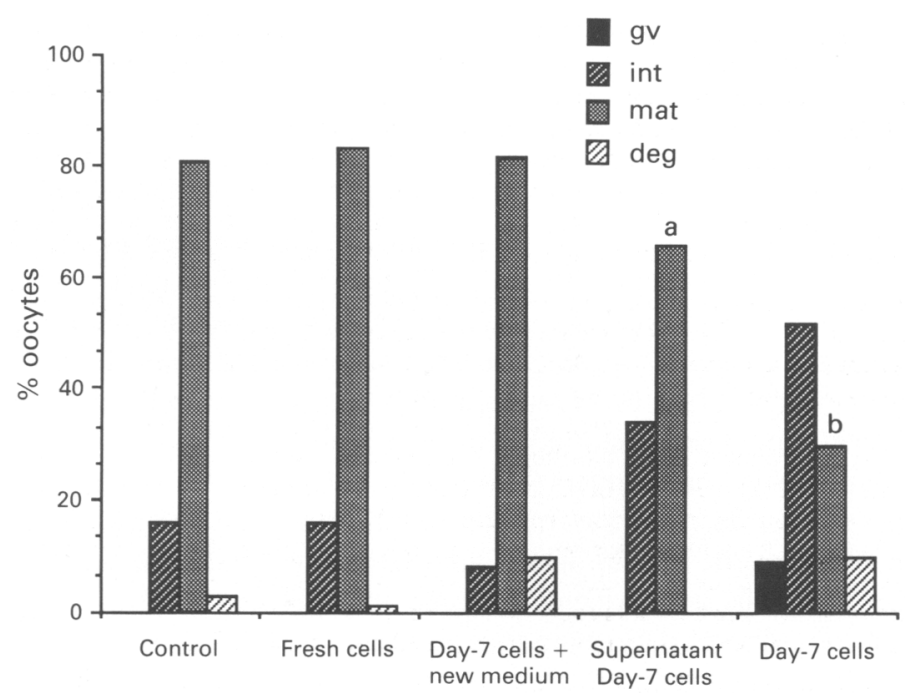

Fig. 1. The effects of different cell-culture conditions on the fraction (\%) of mature bovine oocytes cultured for $24 \mathrm{~h}$. Control $(n=112)$ means no cells and new medium; fresh cells $(n=$ $105)$ indicates a culture with fresh granulosa cells $\left(2 \times 10^{6} / \mathrm{ml}\right)$; Supernatant $(n=59)$ indicates the use of a conditioned medium obtained from granulosa cell culture at Day 7; Day-7-cells means the co-culture with a monolayer of granulosa cells with $(n=60)$ or without $(n=115)$ new medium. Germinal vesicle (gv); from GV to telophase-I (int); maturing (mat); degenerated (deg). With $\chi^{2}$ analysis: (a) indicates a significant difference from control $(P<0.05)$ and (b) indicates a difference compared to (a) and to control $(P<0.05)$.

The effects of the different additives are illustrated in Fig. 2. Heparin or IBMX had no significant effect on meiotic resumption in vitro but adenosine and the combination of adenosine and IBMX significantly inhibited the in-vitro maturation $(P<0 \cdot 05)$. The effect of adenosine \pm IBMX cannot be described as additive since the effect when both products were used together was not different $(P<0.01)$ from that of adenosine alone but was different from that of IBMX alone. Adenosine-containing treatments almost completely inhibited the cumulus expansion during the 
24-h incubation while IBMX stimulated expansion, but the two together resulted in slight or no expansion. Cumulus expansion was also prevented in most cases when the oocytes were adhering rapidly to the monolayers compared to the response in new medium, fresh cells or heparin-monolayer combinations.

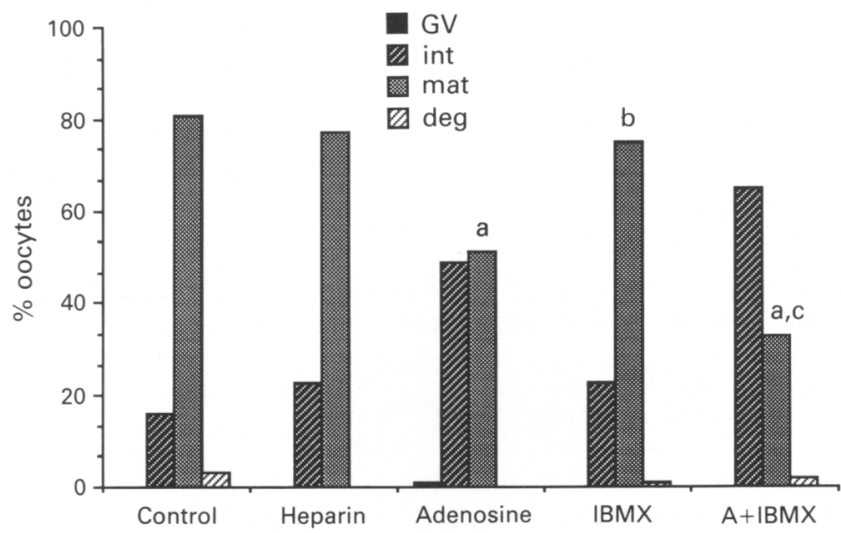

Fig. 2. The effects of different additives on the fraction (\%) of mature bovine oocytes cultured for $24 \mathrm{~h}$. Additives used were IBMX $(n=81)$, IBMX + adenosine $(n=58)$, adenosine alone $(n=57)$, heparin $(n=52)$ and control medium $(n=112)$. Germinal vesicle (gv); from GV to telophase-I (int); maturing (mat); degenerated (deg). With $\chi^{2}$ analysis: (a) indicates a significant difference from control $(P<0.05)$, (b) indicates a difference compared to (a) $(P<0.05)$, and (c) indicates a difference from (b) $(P<0.05)$.

The effects of the combinations of all treatments are summarized in Table 1. A large contingency table was produced to evaluate the main effects of treatments (cells and additives) using all the data available. This analysis revealed specific differences in the fraction of oocytes progressing to maturation indicating a significant effect of adenosine + IBMX and in the cell treatments, a significant effect of the supernatant or the supernatant and cultured cells for 7 days. There was no increase in the number of oocytes remaining at the germinal vesicle stage when adenosine was used in combination with the Day-7 monolayers ( $8 \%$ vs $9 \%$ control) (Table 1 ). The addition of IBMX or IBMX + adenosine did not decrease the fraction of maturing oocytes ( 28 and $27 \% v s 30 \%$ ) when combined with the monolayers, but the IBMX and IBMX + adenosine decreased that rate when compared with the fresh cells used with control medium $(54$ and $52 \%$ vs $83 \%)(P<0.05)$. The effect of heparin on monolayers with their supernatant was different $(P<0.05)$ from that of all other treatments combined and reduced the fraction of immature oocytes obtained after $24 \mathrm{~h}$. The combination of IBMX and Day-7 monolayers with their supernatant was also different $(P<0.05)$ from all other combinations for the fraction remaining at the germinal vesicle stage after $24 \mathrm{~h}$.

\section{Discussion}

The evidence presented in this study indicates that cultured bovine granulosa cells can modify the normal nuclear behaviour of bovine oocytes during in-vitro maturation. This action of cultured follicular cells can be partly transmitted through the conditioned culture medium, indicating a low concentration, a short half-life of the product involved or a limited permeability towards cumulusoocyte complexes. We did not evaluate in this study the extent or the nature of the junction between cultured cells and the cumulus-oocyte complexes with electron microscopy but studies in the rat indicate that granulosa cells can make gap junctions very rapidly with cells as different as mouse myocardial cells and that cAMP can be transferred, also rapidly, from one type of cell to another (Lawrence et al., 1978). Ultrastructural studies of cumulus-oocyte complexes in culture in the rat 
Table 1. Percentages of mature oocytes in the different combinations of additives and cell treatments ( 1630 oocytes were used with a minimum of 25 per treatment)

\begin{tabular}{lcccccc}
\hline & Control & Heparin & Adenosine & IBMX & $\begin{array}{c}\text { Adenosine } \\
\text { +IBMX }\end{array}$ & ANOVA \\
\hline Control & 81 & 77 & 51 & 75 & 33 & a,b \\
Fresh cells & 83 & 81 & 63 & 54 & $52(2)$ & a \\
Day-7 cells + & & & & & & \\
new medium & 82 & 79 & 64 & 71 & 43 & $\mathrm{a}$ \\
Supernatant & 66 & 76 & 59 & 58 & 38 & $\mathrm{~b}$ \\
Day-7 cells & $30(9) \dagger$ & $46(3)$ & $35(8)$ & $28(33)^{*}$ & 27 & $\mathrm{c}$ \\
ANOVA & $\mathrm{a}$ & $\mathrm{a}$ & $\mathrm{b}$ & $\mathrm{a}, \mathrm{b}$ & $\mathrm{c}$ & \\
\hline
\end{tabular}

Values in rows or column with no letters in common are significantly different $(P<0 \cdot 05)$ : Waller-Duncan, ANOVA analysis of variance.

+ Values in parentheses represent the fraction of oocytes remaining at the GV stage.

${ }^{*} P<0.05$ compared to other Day- 7 cell treatments ( $\chi^{2}$ analysis).

also indicate a very rapid change in gap junction morphology following follicular extrusion, and these changes can be modulated by cAMP and the presence or absence of serum (Wert \& Larsen, 1989). The study of Wert \& Larsen (1989) supports the hypothesis that the loss of gap junctions within the cumulus-oocyte complexes would be instrumental in isolating the oocyte from the regulatory influence of its underlying membrana granulosa. When hamster oocytes were transferred to cultured complete follicles, the ability of oocytes to maintain the germinal vesicle depended on the extent of contact between the grafted oocyte and the membrana granulosa after $4 \mathrm{~h}$ (Racowsky \& Baldwin, 1989). The follicular fluid from cows or pigs, lymphocytes or fresh granulosa cells have only a weak inhibition of GVBD in cultured bovine oocytes (Leibfried \& First, 1980). Those results are in agreement with the ones presented here but do not confirm previous publications using pig follicular wall preparations and pig oocytes (Leibfried \& First, 1980). In addition, fresh bovine granulosa cells do not block meiotic resumption since they are used extensively in the in-vitro maturation systems of many authors studying developmental competence in bovine embryos ( $\mathrm{Lu}$ et al., 1987; reviewed by Sirard, 1989).

In laboratory animals, modification of the amount of cAMP in the oocyte, using additives such as dibutyryl cAMP or phosphodiesterase inhibitors, is used to control GVBD (Dekel et al., 1988; Downs et al., 1989). In cattle, a similar approach is not fully successful if the block is to be extended for a period as long as $21 \mathrm{~h}$ but indicates a possible co-factor role since a rise in cAMP will delay GVBD in bovine cumulus-oocyte complexes or denuded oocytes (Sirard \& First, 1988). Homa (1988) used denuded mass-harvested oocytes to evaluate the effects of forskolin, dibutyryl cAMP or IBMX, and cytogenetic analysis revealed that the time of GVBD was delayed compared to that in cumulus-enclosed oocytes (Sirard et al., 1989) but much higher concentrations of cAMP, forskolin or IBMX were required. Homa (1988) also observed a metaphase-I block with cAMP accumulation. In the present study, the use of IBMX resulted in the highest level of meiotic inhibition when added to cultured cells or even with fresh cells, but the same product alone in the control medium was stimulatory rather than inhibitory (Fig. 2). It is possible that, with the amount of IBMX used here $(0 \cdot 2 \mathrm{~mm})$, the presence of excess granulosa cells was required for a maximal effect. There are at least 3 possible explanations of this effect: (1) the phosphodiesterase inhibition is working in additon to factors transmitted or produced in the oocyte to prevent GVBD; (2) IBMX is affecting directly the monolayer's ability to produce or transfer the inhibiting factor to the cumulus-oocyte complexes; or (3) the phosphodiesterase inhibitor enhances contact stimulation, allowing the normal mural granulosa cell signal to be received in the cumulus-oocyte complexes. Heparin, a sulphated glycosaminoglycan for which bovine granulosa cells have receptors, represents a class of membrane protein important in cell-to-cell communication (Bellin et al., 1987). In 
this study, heparin did not enhance a possible contact stimulation and, in fact, interfered with the adhesion of cumulus-oocyte complexes to the monolayers and resulted in higher maturation rates than did other treatments (Table 1). This could indicate a role for this type of glycosaminoglycan in the communication between the cumulus-oocyte complexes and the follicle since atretic follicles accumulate more sulphated glycosaminoglycan-like heparin compared to healthy follicles (Bellin \& Ax, 1984). Additional evidence comes from the fact that a follicular fluid component prevents gonadotrophin reversal of cAMP-dependent meiotic arrest in mouse oocytes (Downs \& Eppig, 1985).

In vivo, bovine granulosa cells are fully competent to maintain meiotic arrest in healthy follicles until the LH surge occurs. Freshly isolated granulosa cells from small follicles do not inhibit GVBD when co-incubated with cumulus-oocyte complexes (this study); bovine follicular fluid or the supernatant from cultured granulosa cells are weak inhibitors of GVBD (Sirard \& First, 1988; present study). Bovine cumulus-oocyte complexes do attach rapidly to granulosa cells in monolayers and this association results in the highest rate of meiotic inhibition. This inhibitory effect can be further improved by IBMX which is inefficient alone. It is therefore likely that an intimate and functional contact between the mural granulosa cells and the cumulus-oocyte complexes is an important signal in itself to maintain meiotic arrest in cattle.

This study was supported by Laval University and a grant from The Natural Sciences and Engineering Research Council of Canada in collaboration with K. J. Betteridge, Guelph, Ontario, Canada.

\section{References}

Ball, G.D., Leibfried, M.L., Ax, R.L. \& First, N.L. (1984) Maturation and fertilization of bovine oocyte in vitro. J. Dairy Sci. 67, 2775-2785.

Bellin, M.E. \& Ax, R.L. (1984) Chondroitin sulfate: an indicator of atresia in bovine follicles. Endocrinology 114, 428-434.

Bellin, M.E., Wentworth, B.C. \& Ax, R.L. (1987) Comparisons of the ability of follicular fluid GAGs and chemically desulfated heparin to compete for heparin-binding sites on granulosa cells. Biol. Reprod. 37, 293-300.

Dekel, N., Galiani, D. \& Sherizly, I. (1988) Dissociation between the inhibitory and stimulatory action of cyclic adenosine monophosphate on maturation of rat oocytes. Molec. cell. Endocr. 56, 115-122.

Downs, S.M. (1989) The maintenance of meiotic arrest in mammalian oocytes. In Fertilization in Mammals (Serono Symp.), p. 3-4.

Downs, S.M. \& Eppig, J.J. (1985) A follicular fluid component prevents gonadotropin reversal of cAMP dependent meiotic arrest in murine oocytes. Gamete Res. 11, 83-97.

Downs, S.M. \& Eppig, J.J. (1987) Induction of mouse oocyte maturation in vivo by perturbants of purine metabolism. Biol. Reprod. 36, 431-437.

Downs, S.M., Daniel, S.A.J., Bornslaeger, E.A., Hoppe, P.C. \& Eppig, J.J. (1989) Maintenance of meiotic arrest in mouse oocytes by purines: modulation of cAMP levels and cAMP phosphodiesterase activity. Gamete Res. 23, 323-334.

Homa, S.T. (1988) Effects of cyclic amp on the spontaneous meiotic maturation of cumulus-free bovine oocytes cultured in chemically defined medium. $J$. exp. Zool. 248, 222-231.
Kuyt, J.R.M., Kruip, T.A.M. \& De Jong-Brink, M. (1988) Cytochemical localization of adenylate cyclase in bovine cumulus-oocyte complexes. Expl Cell Res. 174, 139-145.

Lawrence, T.S., Beers, W.H. \& Gilula, N.B. (1978) Transmission of hormonal stimulation by cell-to-cell communication. Nature, Lond. 272, 501.

Leibfried, M.L. \& First, N.L. (1979) Characterization of bovine follicular oocytes and their ability to mature in vitro. J. Anim. Sci. 48, 76-86.

Leibfried, M.L. \& First, N.L. (1980) Effect of bovine and porcine follicular fluid and granulosa cells on maturation of oocytes in vitro. Biol. Reprod. 23, 699-704.

Lu, K.H., Gordon, I., Gallagher, M. \& McGovern, H. (1987) Pregnancy established in cattle by transfer of embryos derived from in vitro fertilization of oocytes matured in vitro. Vet. Rec. 121, 259-260.

Moor, R.M. \& Heslop, J.P. (1981) Cyclic AMP in mammalian follicle cells and oocytes during maturation. J. exp. Zool. 216, 205-209.

Moor, R.M. \& Trounson, A.O. (1977) Hormonal and follicular factors affecting maturation of sheep oocytes in vitro and their subsequent developmental capacity. J. Reprod. Fert. 49, 101-109.

Pincus, G. \& Enzmann, E.V. (1935) The comparative behavior of mammalian eggs in vitro and in vivo. $J$. exp. Med. 62, 665-675.

Racowsky, C. \& Baldwin, K.V. (1989) In vitro and in vivo studies reveal that hamster oocyte meiotic arrest is maintained only transiently by follicular fluid, but persistently by membrane/cumulus granulosa cell contact. Devl Biol. 134, 297-306.

Sato, E. \& Ishibashi, T. (1977) Meiotic arresting action of the substance obtained from cell surface of porcine Downloaded from Bioscientifica.com at $04 / 26 / 2023$ 11:05:51AM via free access 
ovarian granulosa cells. Jap. J. Zootech. Sci. 48 22-26.

Sato, E. \& Koide, S.S. (1984) A factor from bovine granulosa cells preventing oocyte maturation. Differentiation 26, 59-62.

Sirard, M.A. (1989) Practical aspects of in-vitro fertilization in cattle. J. Reprod. Fert., Suppl. 38, 127-134.

Sirard, M.A. \& First, N.L. (1988) In vitro inhibition of oocyte nuclear maturation in the bovine. Biol. Reprod. 39, 229-234.

Sirard, M.A., Florman, H.M., Leibfried-Rutledge, M.L., Barnes, F.L., Sims, M.L. \& First, N.L. (1989) Timing of nuclear progression and protein synthesis necessary for meiotic maturation of bovine oocytes. Biol. Reprod. 40, $1257-1264$.
Snedecor, G.W. \& Cochran, W.G. (1980) Statistical Methods, p. 507. Iowa State University Press, Ames.

Takahashi, M., Koide, S.S. \& Donahoe, P.K. (1986) Müllerian inhibiting substance as oocyte meiosis inhibitor. Molec. cell. Endocr. 47, 225-234.

Waller, B.A. \& Kemp, K.E. (1976) Computations of Bagesian t-values for multiple comparison. J. Stast. comp. Simulation 75, 169-172.

Wert, S.E. \& Larsen, W.J. (1989) Meiotic resumption and gap junction modulation in the cultured rat cumulus-oocyte complex. Gamete Res. 22, 143-162.

Received 8 September 1989 